ISSN 0103-8478

\title{
Avaliação sensorial de pães de fermentação natural a partir de culturas starters inovadoras
}

\author{
Sensory evaluation of natural fermentation breads with innovative starter cultures
}

\author{
Fernanda Martinbianco ${ }^{I}$ André Rosa Martins ${ }^{I I}$ Rosane Rech ${ }^{\mathrm{I}}$ Simone Hickmann Flôres ${ }^{\mathrm{I}}$ Marco \\ Antônio Záchia Ayub ${ }^{{ }^{*}}$
}

RESUMO

A fermentação sourdough para a produção de pães é fortemente motivada por seus efeitos benéficos quanto ao sabor, textura, vida de prateleira e pelas propriedades nutricionais dos produtos obtidos. Nesta pesquisa, estudou-se a aplicação dos micro-organismos Kluyveromyces marxianus, Dekkera bruxellensis e Lactobacillus plantarum como culturas starters alternativas na produção de pães. A partir de sete ensaios resultantes de um delineamento de mistura simplexcentroide, foram realizadas nos pães análises sensorial $e$ instrumental. Observou-se que pães produzidos com L. plantarum apresentaram menor volume específico, enquanto que a mistura entre $\boldsymbol{K}$. marxianus e $\boldsymbol{L}$. plantarum exerceu influência positiva, possibilitando obter produtos de maior volume específico. A análise sensorial demonstrou a boa aceitabilidade para os pães produzidos com a mistura entre $\boldsymbol{D}$. bruxellensis $\boldsymbol{e} \boldsymbol{K}$. marxianus e para a mistura entre os três micro-organismos. Os resultados deste trabalho demonstram a possibilidade do uso de culturas starters definidas para a fermentação sourdough, que é tradicionalmente obtida sem controle de processo.

Palavras-chave: fermentação natural, sourdough; culturas starters, análise sensorial.

\section{ABSTRACT}

The sourdough fermentation in bread making is strongly motivated due to its beneficial aspects on flavor, texture, shelf life, and the nutritional properties of the obtained products. In this research, the yeasts Kluyveromyces marxianus and Dekkera bruxellensis, and the bacterium Lactobacillus plantarum were used as alternative starter cultures in bread making. Experimental designs generated from simplex-centroid mixture were used in the sensorial analyses of breads. Results have shown that bread obtained with pure cultures of $\boldsymbol{L}$. plantarum presented the smallest specific volume, while the mixture of $\boldsymbol{K}$. marxianus and L. plantarum positively influenced the formation of good specific volume of products. Sensorial analysis showed good acceptability for breads obtained with $\boldsymbol{D}$. bruxellensis and $\boldsymbol{K}$. marxianus mixture, as well as for the mixture of the three microorganisms. The results obtained in this research suggest the possibility of using defined starter cultures for sourdough fermentation, which is traditionally carried out without any process controls.

Key words: natural fermentation, sourdough, starter cultures, sensory analysis.

\section{INTRODUÇÃO}

O sourdough, mistura de farinha e água fermentada com bactérias ácido-láticas e leveduras, é a base para a produção de pão tipo sourdough ou de fermentação natural (DIOWSKSZ \& AMBROZIAK, 2006). Nesse tipo de fermentação, diferentes ácidos orgânicos são produzidos, os quais melhoram o sabor do pão, ajudam na formação da rede de glúten e aumentam a retenção de gás, resultando em produtos com boa textura e volume. Muitas propriedades inerentes do sourdough devem-se à atividade metabólica da bactéria ácido-lática presente no processo: fermentação láctica, proteólise e síntese de compostos voláteis, e ação antifúngica estão entre as atividades mais importantes durante a fermentação (PLESSAS et al., 2011). Além disso, outra vantagem desse método é a extensão da vida de prateleira dos produtos, devido à retenção da umidade e aumento da acidez, o que contribui para o controle microbiano e textura do pão (PLESSAS et al., 2012).

IInstituto de Ciência e Tecnologia dos Alimentos, Universidade Federal do Rio Grande do Sul (UFRGS), Av. Bento Gonçalves, 9500, CP

15091, 91501-970, Porto Alegre, RS, Brasil. E-mail: mazayub@ufrgs.br. *Autor para correspondência.

IIInstituto Federal do Rio Grande do Sul (IFRS), Campus de Porto Alegre, Porto Alegre, RS, Brasil. 
Muito embora a bactéria ácido-lática Lactobacillus plantarum e as leveduras Kluyveromyces marxianus e Dekkera bruxellensis tenham sido identificadas na microbiota natural de massas para pão obtidas por esse método, estes micro-organismos jamais foram utilizados como culturas starters para produzir pão sourdough. O L. plantarum é uma espécie ubíqua, encontrado em diversos ecossistemas alimentares (GOBBETTI et al., 1994; CORSETTI \& GOBBETTI, 2002; BRINQUES et al., 2010), muito provavelmente devido ao seu metabolismo versátil, capacidade de adaptação para diferentes condições ambientais e largo espectro de atividade antimicrobiana (CAGNO et al., 2009). Essa espécie possui características metabólicas interessantes por ser competitiva com outras espécies autóctones da farinha de trigo e/ou biotipos da mesma espécie. A levedura $\boldsymbol{D}$. bruxellensis é geralmente considerada um organismo de contaminação na produção de vinho, mas em algumas aplicações, como, por exemplo, na produção de cerveja do tipo lambic, é considerada como participante desejável da microbiota, contribuindo para o sabor característico do produto (MEROTH et al., 2003). A levedura $\boldsymbol{K}$. marxianus já teve seu uso relatado na panificação como fermento (CABALLERO et al., 1995), mas sua aplicação num processo de fermentação natural não foi estabelecido até agora. Tendo em vista o crescente mercado de produtos alternativos ou que apresentem características únicas, tanto quanto aos aspectos de propriedades nutricionais, como quanto à aceitabilidade sensorial, seria interessante o estudo da produção de pães sourdough de forma mais controlada, como alternativa aos processos naturais, que carecem de controle de processo. Dessa forma, o objetivo deste estudo foi o de avaliar, através de um planejamento de mistura, o uso desses micro-organismos de forma isolada ou em culturas mistas para a produção de pão sourdough e avaliar as suas características sensoriais e físicas.

\section{MATERIAL E MÉTODOS}

\section{Micro-organismos}

Neste trabalho, foram utilizadas as seguintes cepas de micro-organismos: Lactobacillus plantarum BL011, uma bactéria GRAS, isolada de amostras de queijo serrano, conforme metodologia de SOUZA et al. (2003); Dekkera bruxellensis (NRRL Y - 12961), uma cepa comercial de levedura associada à vinificação, doada pelo Center for Agricultural Utilization Research (USA); e Kluyveromyces marxianus CBS 6556, proveniente do Centralbüreau vor Schimmelcultures (Holanda) e fornecida pelo Centro de Desenvolvimento
Biotecnológico (SC, Brasil). As cepas microbianas foram mantidas em culturas-estoques em glicerol (50\%) a $-20^{\circ} \mathrm{C}$, enquanto células para uso imediato foram cultivadas em placas de agar MRS para $\mathbf{L}$. plantarum BL011 ou agar YEPD para as leveduras, mantidas a $4^{\circ} \mathrm{C}$ e renovadas a cada 7 dias.

Produção dos inóculos microbianos para a produção de pães

Para a produção de inóculos, os seguintes procedimentos foram adotados: $\boldsymbol{L}$. plantarum foi cultivada por $24 \mathrm{~h}$ a $37^{\circ} \mathrm{C}$ em meio de cultivo adaptado de BRINQUES et al. (2010) D. bruxellensis NRRL Y 12961 foi crescida por $12 \mathrm{~h}$ a $30^{\circ} \mathrm{C}$ em meio adaptado de USCANGA et al. (2000). $\boldsymbol{K}$. marxianus CBS 6556, foi cultivada por $12 \mathrm{~h}$ a $30^{\circ} \mathrm{C}$ em meio adaptado de LUKONDEH et al. (2005). Todos os cultivos foram realizados em biorreatores de 5L (BBraun, Alemanha), com controle de $\mathrm{pH}$ (5 para $\mathbf{L}$. plantarum; 6 para as duas leveduras), temperatura e agitação (300rpm, 2L ar $\left.\mathrm{L}^{-1} \mathrm{meio} / \mathrm{min}\right)$. Após o crescimento, as biomassas foram recuperadas por centrifugação do meio de cultivo (3.000g, $15 \mathrm{~min}$ a $4^{\circ} \mathrm{C}$ ). A biomassa úmida resultante, contendo $33 \%$ base seca de células, foi usada como inóculo.

\section{Delineamento experimental}

$O$ projeto de mistura simplex-centroide (MONTGOMERY, 2001) foi utilizado para avaliar o efeito da proporção de biomassa de $\boldsymbol{K}$. marxianus $\left(X_{1}\right)$, D. bruxellensis $\left(X_{2}\right)$ e $\boldsymbol{L}$. plantarum $\left(X_{3}\right)$ no inóculo, sobre o volume específico e as características sensoriais dos pães. A concentração de inóculo foi estipulada em $10 \mathrm{~g}$ de inóculo por $100 \mathrm{~g}$ de farinha de trigo. A tabela 1 mostra o delineamento experimental. As proporções de componentes estão expressas como fração mássica da mistura.

Produção e propagação do sourdough em laboratório

A produção e propagação do sourdough foram adaptadas da metodologia de MINERVINI et al. (2007). Farinha de trigo (500g), água declorada (275mL) e inóculo (50g da preparação das misturas simplex-centroide), foram utilizados para preparar $825 \mathrm{~g}$ de massa. O sourdough foi incubado em um recipiente plástico de polipropileno estéril a $28^{\circ} \mathrm{C}$ e, a cada $48 \mathrm{~h}$, foram retirados $165 \mathrm{~g}$ dessa massa e adicionados $110 \mathrm{~g}$ de farinha de trigo e $55 \mathrm{~mL}$ de água declorada até o final da fermentação, após 12 dias (288h).

Produção dos pães

A formulação base adotada para a preparação do pão foi adaptada de ANGIOLINI et 
Tabela 1 - Fração mássica dos componentes K. marxianus $\left(X_{1}\right)$, D. bruxellensis $\left(X_{2}\right)$ e L plantarum $\left(X_{3}\right)$ que compõem o delineamento da mistura Simplex-centroide.

\begin{tabular}{lccc}
\hline Mistura & $X_{1}$ & $X_{2}$ & $X_{3}$ \\
& K. marxianus & D. bruxellensis & 0 \\
\hline 1 & 1 & 0 & 0 \\
2 & 0 & 1 & 1 \\
3 & 0 & 0 & 0,5 \\
4 & 0 & 0,5 & 0,5 \\
6 & 0,5 & 0 & 0 \\
7 & 0,5 & 0,5 & 0,33 \\
\hline
\end{tabular}

al. (2006): farinha de trigo, 1.000g; sourdough, 300g; açúcar demerara, 200g; leite em pó, 50g; gordura, 50g; sal, 20g; e água, 500g.

Volume específico

O volume específico foi calculado pela relação entre o volume do pão assado, determinado pelo método de deslocamento de sementes de painço (HALLEN et al., 2004).

Análise sensorial

Os pães obtidos foram submetidos ao teste sensorial de aceitação (DUTCOSKI, 2007), com 40 provadores, para os atributos sabor e avaliação global, utilizando escalas ancoradas em: 1 - desgostei muitíssimo e 9 - gostei muitíssimo. Os testes foram realizados em duas sessões. Em cada sessão, foram avaliadas quatro formulações diferentes, sendo que o ponto central (mistura 7) foi analisado nas duas sessões. Os dados foram analisados através da metodologia de análise de superfície resposta para planejamento de mistura (Simplex-Centroide), usando o software Statistica 10.0.

\section{RESULTADOS E DISCUSSÃO}

Volume específico

Os resultados de volume específico dos diferentes experimentos estão mostrados na tabela 2. O pão produzido somente com L. plantarum foi o que apresentou o menor volume específico $\left(1,29 \mathrm{~cm}^{3} \mathrm{~g}^{-1}\right)$, possivelmente ocasionado pelo metabolismo homofermentativo da bactéria, pois essa cepa possui metabolismo heterofermantativo facultivo (GOBBETTI et al., 2005), produzindo menos gás carbônico do que o normalmente obtido em fermentações com leveduras. É possível que o longo tempo de fermentação (288h) tenha favorecido o metabolismo homofermentativo, no qual não há produção de gás carbônico. Além disso, conforme GOBBETTI et al. (1994), o volume do pão é dependente, sobretudo, do desenvolvimento adequado das leveduras.

O volume específico obtido da composição pura dos micro-organismos variou entre $1,29 \mathrm{~cm}^{3}$ $\mathrm{g}^{-1}$ e $2,57 \mathrm{~cm}^{3} \mathrm{~g}^{-1}$ e, para a mistura dos três microorganismos, foi de $2,87 \mathrm{~cm}^{3} \mathrm{~g}^{-1}$, e o volume obtido para as misturas binárias variaram entre $2,84 \mathrm{~cm}^{3} \mathrm{~g}^{-1}$ e $3,91 \mathrm{~cm}^{3} \mathrm{~g}^{-1}$. PLESSAS et al. (2008) produziram pães sourdough com 16h de fermentação e diferentes combinações e quantidades de $\boldsymbol{K}$. marxianus, Lactobacillus bulgaricus e Lactobacillus helveticus, obtendo volume específico variando entre $2,0 \mathrm{~cm}^{3} \mathrm{~g}^{-1}$ e $2,3 \mathrm{~cm}^{3} \mathrm{~g}^{-1}$.

A figura 1a mostra a variação do volume específico, conforme a composição do inóculo. O sistema binário K. marxianus e L. plantarum produziu pão com maior volume específico, já a mistura ternária produziu pão com volume médio entre as amostras. Os menores valores foram obtidos na cultura de $\boldsymbol{L}$. Plantarum pura. Os resultados obtidos sugerem que tanto a retenção como a produção de gás na massa foram influenciadas pelas diferentes culturas starter utlizadas para fermentar a massa. O volume específico do pão depende de dois fatores: da quantidade de gás produzido e da capacidade de retenção do gás no sistema de massa, que depende do grau de hidratação das proteínas insolúveis gliadinas e gluteninas, presentes na farinha (CLARKE et al., 2003). A tecnologia aplicada à massa e o tipo de cultura starter produzem efeitos diferentes sobre a produção global de gás. Assim, as propriedades 


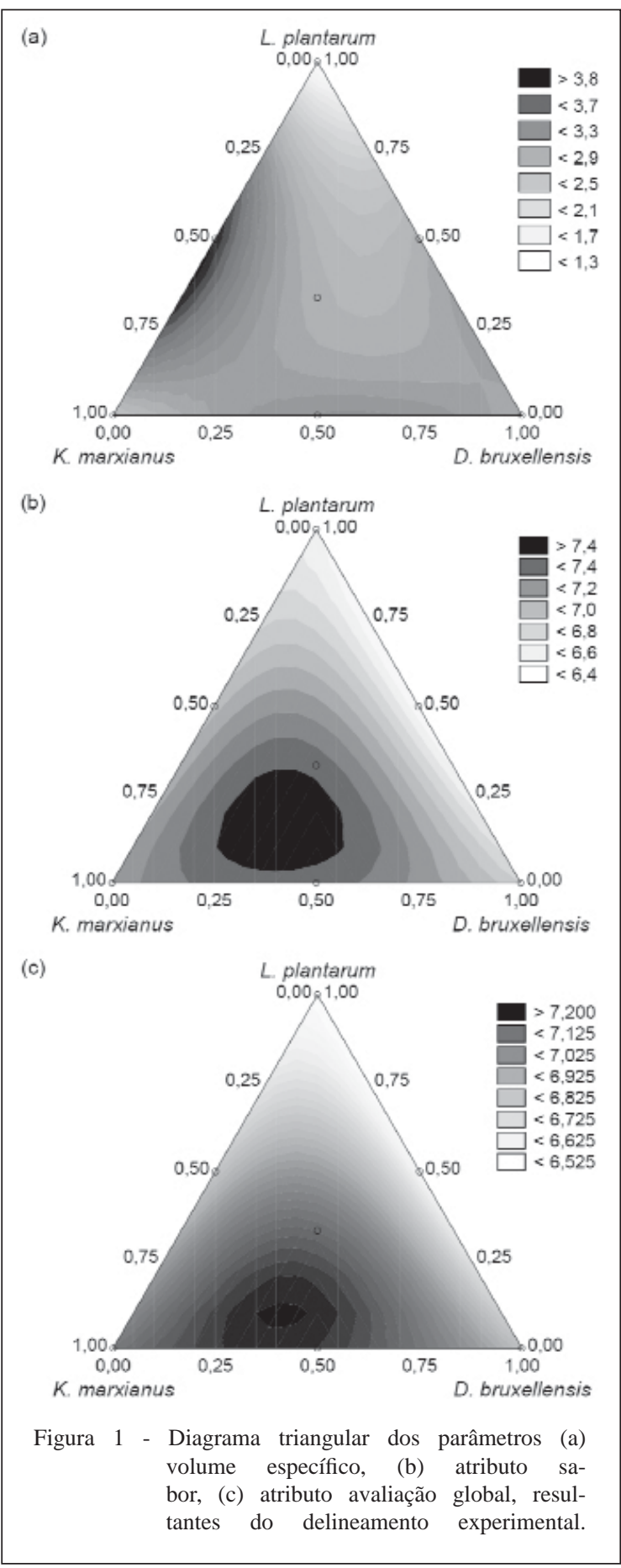

específicas da cultura inicial devem ser consideradas (HAMMES \& GANZLE, 1998).

\section{Análise sensorial}

Os pães produzidos conforme delineamento experimental foram submetidos ao teste de aceitação para dois atributos: sabor e avaliação global. Os resultados estão apresentados na tabela 2 .
Tanto o sabor quanto a aceitação global foram satisfatoriamente representados pelo modelo de regressão proposto, com altos coeficientes de determinação, 0,9997 e 0,9975, respectivamente. As figura 1b e figura 1c mostram as superfícies de resposta dos atributos sabor e aceitação global com a composição do inóculo. Ambos atributos possuem comportamento similar, já que a aceitação global é fortemente influenciada pelo sabor. O pão inoculado com $\boldsymbol{L}$. plantarum puro recebeu as avaliações mais negativas, e a adição de $\boldsymbol{D}$. bruxellensis ao inóculo de $\boldsymbol{L}$. plantarum não levou a melhores avaliações em ambos os atributos. Já a adição de $\boldsymbol{K}$. marxianus levou a um aumento das notas. Através da análise das superfícies, para uma maior aceitação, o inóculo deve conter no máximo $25 \%$ de $\boldsymbol{L}$. plantarum, entre $25 \%$ e $50 \%$ de $\boldsymbol{D}$. bruxellensis e entre 50\% e 75\% de $\mathbf{K}$. marxianus.

RIZZELLO et al. (2010), trabalhando com culturas de $L$. plantarum, L. rossiae, e sourdough a base de gérmen de trigo e com 24h de fermentação obteve nota média 6,8 para o atributo sabor em escala de 9 pontos. MAJISOLA (2011), com sourdough a base de farinha de milho, tempo de fermentação de $24 \mathrm{~h}$ e utilizando uma mistura de $\boldsymbol{L}$. plantarum, $\boldsymbol{L}$. brevis e $\boldsymbol{L}$. mesenteroides obteve na avaliação sensorial dos atributos sabor e avaliação global, nota 4,8 (escala hedônica de 5 pontos).

De modo geral, os pães produzidos, neste trabalho, obtiveram boa aparência. Porém, alguns provadores constataram, no sabor do pão, acidez elevada, característico desse tipo de fermentação prolongada, que pode ter contribuído para que as avaliações do sabor e do atributo avaliação global não tivessem ultrapassado a média 7,4 (Tabela 2)

A acidez é uma característica da fermentação sourdough e a produção de ácido durante a fermentação depende de vários fatores, tais como a composição da farinha, tempo e temperatura de fermentação e principalmente dos micro-organismos presentes (DE VUYST et al., 2002). Assim, a escolha adequada da estirpe de bactéria ácida lática é decisiva para a qualidade do pão. De igual importância é a relação entre ácido láctico e ácido acético. O primeiro, principalmente, influencia na estrutura do miolo, enquanto que o último é componente chave no sabor do pão (GOBBETTI et al., 1994). No entanto, uma produção excessiva de ácido acético é desfavorável, uma vez que provoca acidez intensiva, o que é inaceitável para o consumidor.

\section{CONCLUSÃO}

Baseado nos modelos obtidos através da aplicação do delineamento experimental de mistura, 
Tabela 2- Média e desvio padrão resultantes do delineamento experimental Simplex-Centroide*, utilizado para avaliar o efeito da biomassa de K. marxianus $\left(X_{1}\right)$, D. Bruxellensis $\left(X_{2}\right)$ e L plantarum $\left(X_{3}\right)$ sobre o volume específico, o atributo sabor e aceitação global dos pães.

\begin{tabular}{|c|c|c|c|c|c|c|}
\hline Mistura & K. marxianus & D. bruxellensis & L. plantarum & $\begin{array}{l}\text { Volume } \\
\text { específico } \\
\left(\mathrm{cm}^{3} \mathrm{~g}^{-1}\right)\end{array}$ & Sabor & Avaliação global \\
\hline 1 & 1 & 0 & 0 & $2,57 \pm 0,04$ & $7,1 \pm 1,8$ & $7,1 \pm 1,6$ \\
\hline 2 & 0 & 1 & 0 & $2,90 \pm 0,01$ & $6,8 \pm 1,5$ & $6,9 \pm 1,5$ \\
\hline 3 & 0 & 0 & 1 & $1,29 \pm 0,11$ & $6,5 \pm 1,9$ & $6,5 \pm 1,7$ \\
\hline 4 & 0 & 0,5 & 0,5 & $2,84 \pm 0,04$ & $6,4 \pm 1,8$ & $6,6 \pm 1,5$ \\
\hline 5 & 0,5 & 0 & 0,5 & $3,91 \pm 0,06$ & $7,0 \pm 1,5$ & $6,8 \pm 1,5$ \\
\hline 6 & 0,5 & 0,5 & 0 & $3,22 \pm 0,08$ & $7,4 \pm 1,2$ & $7,3 \pm 1,1$ \\
\hline 7 & 0,33 & 0,33 & 0,33 & $2,87 \pm 0,22$ & $7,4 \pm 1,0$ & $7,2 \pm 1,0$ \\
\hline
\end{tabular}

(*) Metodologia de superfície de resposta para mistura (Simplex-Centroide); nível de significância = 0,05; erro puro calculado através da repetição do ponto central.

observou-se a influência significativa dos componentes puros, para atributo sabor, aceitação global e para o volume específico do pão. A utilização de L. plantarum puro como inóculo levou aos menores valores de volume específico e menores notas de sabor e aceitação global. Além disso, através dos dados obtidos, conclui-se que a tendência para obter pães com melhor qualidade é para misturas com maiores quantidades de $\boldsymbol{K}$. marxianus. Assim, é possível projetar novas misturas de cepas que possam ser utilizadas como culturas de partida para a fermentação “sourdough”, visando melhorar o volume, o sabor ou a aceitação do pão.

\section{COMITÊ DE ÉTICA}

Para a realização da análise sensorial, todos os provadores receberam o termo de consentimento aprovado pelo comitê de ética da UFRGS (protocolo no: 21081/2012), por estarem de acordo com a Resolução 196/96 e complementares do Conselho Nacional de Saúde.

\section{REFERÊNCIAS}

ANGIOLINI, A. et al. Characteristics of bread making doughs: influence of sourdough fermentation on the fundamental rheological properties. European Food Research and Technology, Berlin, v. 222. p.54-57, 2006. Disponível em: <http://dx.doi.org/10.1007/ s00217-005-0087-x>. Acesso em: 01 jan. 2012. doi: 10.1007/ s00217-005-0087-x.

BRINQUES, G.B. et al. Optimization of probiotic and lactic acid production by Lactobacillus plantarum in submerged bioreactor systems. Journal of Industrial Microbiology and Biotechnology, Hampshire, v.37, n.2, p.205-212, 2010. Disponível em: < http://dx.doi.org/10.1007/s10295-009-0665-1>. Acesso em: 08 mar. 2012. doi:10.1007/s10295-009-0665-1.

CABALLERO, R. et al. Evaluation of Kluyveromyces marxianus as baker's yeast. Food Research International, Barking, v.28, n.1, p.37-41, 1995. Disponível em: <http://dx.doi.org/10.1016/09639969(95)93329-S>. Acesso em: 01 jan. 2012. doi: 10.1016/09639969(95)93329-S.

CAGNO, R. et al. Molecular adaptation of sourdough Lactobacillus plantarum DC400 under co-cultivation with other lactobacilli. Research in Microbiology, Paris, v.160, p.358-366, 2009. Disponível em: <http://dx.doi.org/10.1016/j. resmic.2009.04.006>. Acesso em: 01 jan. 2012. doi: 10.1016/j. resmic.2009.04.006.

CLARKE, C.I. et al. Use of response surface methodology to investigate the effects of processing conditions on sourdough wheat bread quality. European Food Research and Technology, Berlin, v.217, p.23-33, 2003. Disponível em: <http://dx.doi. org/10.1007/s00217-003-0724-1>. Acesso em: 08 mar. 2012. doi: 10.1007/s00217-003-0724-1.

CORSETTI, A.; GOBBETTI, M. Lactobacillus plantarum. In: PROGINSLI, H. et al. (Ed.). Encyclopedia of dairy sciences. New York: Academic, 2002. p.1501-1507.

GOBBETTI, M. et al. The sourdough microflora. Interaction between lactic acid bacteria and yeasts: metabolism of carbohydrates. Applied Microbiology and Biotechnology, Berlin, v.41, p.456-460, 1994. Disponível em: <http://dx.doi.org/10.1007/BF01982535>. Acesso em: 15 nov. 2012. Acesso em: 21 abr. 2012. doi: 10.1007/ BF01982535.

GOBBETTI, M. et al. Biochemistry and physiology of sourdough lactic acid bacteria. Trends in Food Science and Technology, Cambridge, v.1, p.57-69, 2005. Disponível em: <http://dx.doi. 
org/10.1016/j.tifs.2004.02.013>. Acesso em: 02 fev. 2012. doi: 10.1016/j.tifs.2004.02.013.

HALLEN, E. et al. Effect of fermented/germinated cowpea flour addition on the rheological and baking properties of wheat flour. Journal of Food Engineering, Essex, v.63, n.2, p.177184, 2004. Disponível em: <http://dx.doi.org/10.1016/S02608774(03)00298-X>. Acesso em: 12 ago. 2012. doi: 10.1016/ S0260-8774(03)00298-X.

HAMMES, W.P.; GANZLE, M.G. Sourdough breads and related products. In: WOOD, B.J.B. (Ed.). Microbiology of fermented foods. 2.ed. London: Blackie Academic \& Professional, 1998. V.1. p.199-216.

LUKONDEH, T. et al. Fed-batch fermentation for production of Kluyveromyces marxianus FII 510700 cultivated on a lactose-based medium. Journal of Industrial Microbiology \& Biotechnology, Hampshire, v.32, n.7, p.284-288, 2005. Disponível em: <http://dx.doi.org/10.1007/s10295-005-0245-y>. Acesso em: 17 jan. 2012. doi: 10.1007/s10295-005-0245-y.

MAJISOLA, O.E. A modified sourdough procedure for nonwheat bread from maize meal. Food Bioprocess Technology, New York, v.4, n.7, p.1264-1272, 2011. Disponível em: <http:// dx.doi.org/10.1007/s11947-009-0252-5>. Acesso em: 01 abr. 2013. doi: 10.1007/s11947-009-0252-5.

MEROTH, C.B. et al. Identification and population dynamics of yeasts in sourdough fermentation processes by PCR-denaturing gradient gel electrophoresis. Applied and Environmental Microbiology, Washington, v.69, p.7453-7461, 2003. Disponível em: <http://dx.doi.org/10.1128/AEM.69.12.7453-7461.2003>. Acesso em: 20 set. 2012. doi: 10.1128/AEM.69.12.74537461.2003

MINERVINI, F. Robustness of Lactobacillus plantarum starters during daily propagation of wheat flour sourdough type I. Food Microbiology, London, v.27, n.7, p.897-908, 2007. Disponível em: <http://dx.doi.org/10.1016/j.fm.2010.05.021>. Acesso em: 02 nov. 2012. doi: 10.1016/j.fm.2010.05.021.
MONTGOMERY, D.C. Design and analysis of experiments. 5.ed. USA: John Wiley \& Sons, 2001. 684p.

PLESSAS, S. et al. Application of Kluyveromyces marxianus, Lactobacillus delbrueckii ssp. L. bulgaricus and L. helveticus for sourdough bread making. Food Chemistry, London, v.106, p.985-990, 2008. Disponível em: <http://dx.doi.org/10.1016/j. foodchem.2007.07.012>. Acesso em: 01 abr. 2012. doi: 10.1016/j. foodchem.2007.07.012.

PLESSAS, S. et al. Application of novel starter cultures for sourdough bread production. Anaerobe, London, v.17, p.486-489, 2011. Disponível em: < http://dx.doi.org/10.1016/j.anaerobe.2011.03.022>. Acesso em: 24 dez. 2012. doi: 10.1016/j.anaerobe.2011.03.022.

PLESSAS, S. et al. Kefir immobilized on corn grains as biocatalyst for lactic acid fermentation and sourdough bread making. Journal of Food Science, Washington, v.77, p.1256-1262, 2012. Disponível em: $<$ http://dx.doi.org/10.1111/j.1750-3841.2012.02985.x>. Acesso em: 02 nov. 2012. doi: 10.1111/j.1750-3841.2012.02985.x.

RIZZELLO, C.G. et al. Use of sourdough fermented wheat germ for enhancing the nutritional, texture and sensory characteristics of the white bread. European Food research Technology, London, v.230, p.645-654, 2010. Disponível em: <http://dx.doi.org/10.1007/ s00217-009-1204-z>. Acesso em: 20 set. 2012. doi: 10.1007/s00217009-1204-z.

SOUZA, C.F.V. et al. Changes in the microbiological and physicochemical characteristics of Serrano cheese during manufacture and ripening. Brazilian Journal of Microbiology, São Paulo, v.34, n.3, p.260-266, 2003. Disponível em: <http://dx.doi.org/10.1590/ S1517-83822003000300016>. Acesso em: 01 jan. 2012. doi: 10.1590/ S1517-83822003000300016.

USCANGA M.G.A. et al. Nutritional requirements of Brettanomyces bruxellensis: growth and physiology in batch and chemostat cultures. Canadian Journal Microbiology/Revue Canadienne de Microbiologie, Ottawa, v.46, n.11, p.1046-1050, 2000. Disponível em: <http://dx.doi.org/10.1139/w00-089>. Acesso em: 07 set. 2012. doi: $10.1139 /$ w00-089 